\title{
trabalhonecessário
}

issn: $1808-799 \mathrm{X}$

ano 8 - número 10 - 2010

\section{COTIDIANO DA UNIVERSIDADE PÚBLICA, TRABALHO DOCENTE E LEI DE INOVAÇÃO TECNOLÓGICA.}

\author{
Pedro Henrique de Sousa Tavares ${ }^{1}$ - pedromica_@hotmail.com
}

\section{Resumo:}

Este texto procura discutir o surgimento de um novo cotidiano nas universidades públicas e seus desdobramentos sobre o trabalho docente. Tomando o inicio das reformas neoliberais na educação, o trabalho discorre sobre a aproximação das universidades e seus modelos organizacionais e de gestão com os paradigmas do mercado. Para o melhor entendimento problematizamos a Lei de Inovação Tecnológica dentro das reformas educacionais e suas conseqüências sobre a natureza e identidade do trabalho docente.

Palavras-chaves: reformas, flexibilização, cotidiano universitário, trabalho docente.

\section{Abstract}

This text search discuss the emergence of a new daily public universities and their ramifications on professor work. Taking the neoliberal reforms in education, work, discuss the approximation of the universities and their organizational and management models with the paradigms of the market.

For better understanding, we problematize the law of technological innovation within educational reforms and its consequences on the nature and identity of professor work.

Keywords: reforms, relaxation, daily universitario, professor work.

\footnotetext{
${ }^{1}$ Estudante de Ciências Sociais da Universidade Federal do Pará, membro do Grupo de Estudos sobre Política Educacional e Trabalho docente, do Instituto de Ciências da Educação da mesma universidade, bolsista de iniciação cientifica do CNPq, e-mail: pedromica@ @ hotmail.com .
} 
issn: 1808-799X

ano 8 - número 10 - 2010

\section{Considerações Iniciais}

As duas últimas décadas demarcaram mudanças nas políticas educacionais brasileiras, traduzindo a nova regulação das políticas sociais.

Desta forma como conseqüência destas políticas a educação superior passou por varias transformações, que acompanharam o movimento geral da lógica das políticas implementadas, que podem estar fazendo surgir um novo cotidiano universitário nas universidades públicas, bem diferente do cotidiano do contexto das reformas que marcaram o cenário político-econômico a partir dos anos 1990, sobretudo com o chamado paradigma gerencial.

Esse novo cotidiano afetou, sobretudo, os trabalhadores docentes, que passaram a responder por novas demandas e incorporar novas funções, alterando a sua identidade profissional e sua natureza de trabalho.

Assim, o texto procura problematizar essas novas demanda e as conseqüências deste novo cotidiano para o trabalhador docente dentro do contexto da Lei de Inovação Tecnológica (Lei 10973/2004).

Para isso procuro no decorrer do texto fazer uma breve análise das reformas neoliberais e das implicações da mudança paradigmática no mundo do trabalho, do fordismo para o modelo de acumulação flexível, e das reformas neoliberais que produziram uma reestruturação produtiva, adequando as economias às novas demandas do capital internacional.

As reformas educacionais são contextualizadas para a compreensão da deregulação em setores que eram historicamente mantidos pelo Estado, como o caso das universidades públicas e da educação superior e das metamorfoses pela qual estão passando, com a hipótese de que surge um novo cotidiano universitário.

Em seguida a forma como se afetou o trabalho e o trabalhador docente com a lei de inovação tecnológica.

\section{Reformas Neoliberais e Trabalho Flexível}

A partir dos anos 1970 inicia-se no mundo capitalista, depois de um longo período de crescimento econômico, uma crise, que para alguns autores 
representou o esgotamento do modelo fordista-keynesiano de produção, incitando um novo modelo ou paradigma produtivo: o toyotismo.

A crise econômica e fiscal pressionava por um lado os Estados Nacionais a abrir suas economias, e por outro lado a manter as economias estáveis. Os Estados passaram a aumentar a emissão de moedas, produzindo a estagflação.

A crise econômica também levou um conjunto de países periféricos a uma crise de endividamento. A saída para a crise era a reestruturação e o reajuste fiscal de suas economias, levando os países periféricos a iniciar um processo de reforma em suas economias, influenciado sobremaneira pelos organismos do capital internacional, como uma forma de gerar superávit para o pagamento da dívida externa, e neste cenário os organismos multilaterais de financiamento, tendo à frente o Grupo Bando Mundial, passam a ter ingerência nos programas de reajuste fiscal dos paises periféricos (CHAVES, 2001).

Essas reformas implicaram busca pelo equilíbrio orçamentário pela redução dos gastos públicos, abertura comercial e liberalização financeira, privatizações e terceirizações das empresas públicas, entre outras medidas.

Essa conjuntura impôs um novo modelo de acumulação, denominado de acumulação flexível, fundamentado na flexibilidade dos processos de trabalho, mercado de trabalho e nos padrões de consumo, na contramão da rigidez do fordismo (CHAVES, MAUÉS, MANCEBO, 2006).

Os defensores da nova forma de acumulação capitalista defendiam a transferência das responsabilidades do Estado para o mercado, apontado como o ente capaz de restabelecer o equilíbrio econômico, em face de sua neutralidade.

Esses fatos geraram a necessidade de reformas no Estado que fossem capazes de responder às demandas da nova ordem mundial e de uma nova vertente que se configurava hegemônica. Construiu-se o mito da falência do Estado e uma concepção de Estado mínimo, reconceituando as esferas do público e privado, perante uma nova vertente hegemônica da economia, fundamentado na dualidade setor estatal de privilégios versus setor privado de eficiência, produzindo um consenso errôneo sobre a ineficiência dos sistemas de ensino públicos (GENTILI, 1998). O processo de corte de gastos sociais e a 
issn: $1808-799 \mathrm{X}$

ano 8 - número 10 - 2010

criação de política de privatização e mercantilização dos serviços públicos também é central na nova forma de organização do Estado.

Ante as reformas apresentam-se mudanças estruturais no seio do processo produtivo, quais sejam as tecnologias que substituíram o trabalho vivo pelo trabalho morto e as novas formas de gestão e organização do trabalho, mais flexíveis, crescendo os contratos temporários e os subempregos. Modificou-se a estrutura e as relações de trabalho com a anuência do Estado a partir de reformas que tornaram a legislação trabalhista também mais flexível.

Maués (2005) analisa as reformas implementadas e as conseqüências para os trabalhadores a partir da mudança no paradigma da produção, sob o paradigma tecnológico/informacional em uma nova etapa do capitalismo, o neoliberalismo, e sua nova forma de produção, flexível. A autora analisa como as reformas procuraram a adequação às mudanças e a superação da crise, ou seja, como "as reformas podem ser analisadas como formas de arranjos que facilitem um reordenamento social e político a partir dos novos padrões de produção" (p. 6).

É no marco das conseqüências dessas reformas e das mudanças emanadas para as relações de trabalho, sobretudo para o trabalho docente, inserido na lógica da relação de produção e acumulação em curso na sociedade capitalista.

\section{Reformas educacionais e um novo cotidiano universitário}

As reformas implementadas nos países periféricos atingiram os setores que eram historicamente mantidos pelo Estado, como a educação, saúde e previdência, que na nova forma de acumulação passam a ser regidos pelo mercado.

A implementação das reformas educacionais no Brasil por sucessivos governos traduz a opção política pelo setor privado que balizou a reforma de conjunto do Estado brasileiro. A referência histórica é o Governo Collor de Mello (1990-1992), que proclamou a superioridade do setor privado sobre o estatal (MANCEBO, MAUÈS, CHAVES, 2006).

As reformas educacionais devem ser compreendidas neste caso como uma relação de poder que tem como fio condutor os objetivos dos países 
issn: $1808-799 \mathrm{X}$

ano 8 - número 10 - 2010

centrais e a consagração do mercado como o definidor das ações numa nova etapa do capitalismo (MAUÉS, 2005).

Entre as recomendações do receituário neoliberal para a educação está o princípio de que os sistemas educacionais também devem se adequar às reformas, tornando-se mais diversificados e flexíveis. Esta tese é defendia pelos organismos internacionais do capital, sobretudo o Banco Mundial (1994) em documento que foi referência na reforma da educação superior para os países periféricos.

Destaca-se neste processo o racionalismo econômico que produziu uma política de realocação dos recursos públicos destinados à educação, apontando centralidade à educação básica, em detrimento da educação superior. Esta política implementada pelos governos cortou recursos da educação superior, e produziu profundas alterações na dinâmica da universidade com grande repercussão sobre o trabalho docente.

Chaves (2006, p. 1) argumenta que as mudanças hoje no campo da educação superior são "parte do movimento de transição do modelo fordista para o regime de acumulação flexível", estruturados pela minimização do tamanho do Estado e pela abertura dos setores sociais ao mercado.

$\mathrm{Na}$ reforma do aparelho do Estado no Brasil (1995) instituiu-se o chamado paradigma gerencial, que demarcou e reafirmou uma nova orientação na gestão dos serviços públicos cuja principal característica era a racionalização dos recursos, gestão direcionada para resultados, flexibilidade de gestão e descentralização. Estes princípios foram adotados como base para o serviço publico, entre os quais estava a educação. Ainda na reforma do aparelho do Estado no Brasil a educação foi definida como uma atividade não exclusiva do Estado, significando que poderia ser compartilhada com o setor empresarial, num quase mercado.

O argumento da necessidade da diversificação das fontes de financiamento nas universidades públicas diante do cortes e da redução orçamentária veio, neste sentido, produzindo uma reforma universitária que consagra a privatização a as parcerias com o setor privado, produzindo conseqüências diretas sobre o trabalho docente. 
issn: $1808-799 \mathrm{X}$

ano 8 - número 10 - 2010

Entre os argumentos que justificam essa mudança institucional destacam-se aqueles que defendem a reforma da educação superior para torná-la mais ágil, diversificada e flexível, para se ter mais competitividade. A esse fenômeno Chauí (2003) chamou de consagração da universidade operacional, prestadora de serviços, que desresponsabilizou o Estado pelo seu custeio:

\begin{abstract}
Regida por contratos de gestão, avaliada por índices de produtividade, calculada para ser flexível, a universidade operacional está estruturada por estratégias e programas de eficácia organizacional, e, portanto, pela particularidade e instabilidade dos meios e objetivos. Definida e estruturada por normas e padrões alheios ao conhecimento e à formação intelectual, sta pulverizada em microorganizações que ocupam seus docentes e curvam seus estudantes a exigências exteriores ao trabalho intelectual (p.3).
\end{abstract}

Chaves (2006, p. 6) pondera sobre isso, demonstrando como "as IFES passaram a buscar na prestação de serviços no mercado o caminho para gerar receitas, visando a complementação salarial e [...] reduzir a penúria produzida pela política governamental". Paralelamente abria-se a discussão sobre a autonomia universitária, entendida segundo os princípios do paradigma gerencial pela capacidade da universidade de captar recursos na sociedade civil e no mercado, aumentando desta forma a porta de um processo neoliberal que adentrou as universidades públicas, tendo como um ator importante as Fundações Privadas.

Institucionalizou-se uma universidade prestadora de serviços, fundamentada e dependente do capital privado, com traços produtivistas e pragmáticos, perdendo a autonomia do saber, subordinando a pesquisa aos interesses do mercado.

Com essas mudanças podemos perceber na universidade pública brasileira a mudanças de seu ethos acadêmico "no qual critérios de produtividade e eficácia organizacional sobrepõem aos objetivos da instituição social caracterizada pela universalidade na produção e transmissão da experiencia cultural e cientifica da sociedade e pela liberdade de discussão e espírito critico, para configurá-la como organização social, transformando a

TrabalhoNecessário - www.uff.br/trabalhonecessario; Ano 8, № 10/2010. 
ano 8 - número 10 - 2010

universidade numa organização prestadora de serviços, com estrutura de gestão voltada para arbitragem de contratos" (CHAVES; MENDES, 2009).

Esses novos traços da educação superior apontam para a criação de um novo cotidiano na universidade, refletidas em grande parte pela adoção sem questionamentos do paradigma gerencial, numa instituição que passa a refletir as contradições da nova ordem mundial e da globalização. Estas mudanças afetaram de forma profunda os trabalhadores docentes.

Esse novo cotidiano nas relações de trabalho também refletiu a flexibilização que norteou a reestruturação produtiva. Chaves (2006) afirma que estas mudanças afetam e desvalorizam o trabalho docente, controlado agora pela nova lógica racionalizadora do capital, perdendo sua autonomia e que depende do mercado para sua continuidade ou não.

\section{Lei de Inovações Tecnológicas e o Trabalho Docente - Professor de Pires na mão?}

As reformas educacionais orientadas na lógica do enxugamento dos gastos públicos trouxeram para o trabalhador docente uma precarização muito grande, evidenciando a flexibilização do trabalho docente. Acentuou-se na universidade pública brasileira um modelo de gestão empresarial, com conseqüências diretas sobre o trabalho docente, com repercussão sobre a natureza das atividades desenvolvidas por esse trabalhador (MAUÉS, 2006).

Entre as reformas da educação superior em curso em curso, que consagraram a superioridade do mercado sobre o setor público e contribuíram para estas metamorfoses que evidenciamos no ethos acadêmico e no cotidiano da universidade, podemos destacar a Lei de Inovação Tecnológica - Lei 10973/2004 (BRASIL, 2004) no Governo Luís Inácio Lula da Silva, ainda em seu primeiro mandato (2003-2006). Essa Lei estabeleceu as medidas de incentivo à inovação e à pesquisa científica e tecnológica no ambiente produtivo, inserida dentro dos marcos da aproximação da parceria do mercado com as universidades, refere-se aos incentivos sobre a inovação e pesquisa cientifica e tecnológica, procurando estabelecer parcerias estratégicas.

Para Sguissard (2009) esta lei representa a concretização do imediatismo empresarial no campo da ciência e da tecnologia, com grandes 
issn: $1808-799 \mathrm{X}$

ano 8 - número 10 - 2010

riscos para a autonomia universitária e a liberdade, produzindo um traço marcante na característica das universidades contemporâneas: a heteronomia.

Esta lei representou a flexibilização das estruturas de financiamento da educação superior e também das condições de trabalhos do docente, consagrando as parcerias público-privadas na educação, principio basilar do neoliberalismo.

Para o trabalho docente, entre as conseqüências da aplicação dessa legislação destacam-se o aumento da competitividade individual entre os professores por recursos, com gratificações diferenciadas segundo o projeto financiado, alterando a cultura acadêmica e produzindo um docente submetido à frenética lei do mercado.

Leda (2006) afirma que essa competitividade no ambiente acadêmico se alastra para além do espaço de trabalho, como a vida pessoal e familiar, com desdobramentos e implicações diversos, criando uma nova relação do docente com o tempo de trabalho. Esta opinião é compartilhada por Mancebo (2007), reafirmando que o professor cria uma nova relação com o tempo de trabalho, resultado direto deste novo cotidiano universitário, na qual se verifica uma aceleração da produção docente, refletindo uma aceleração na jornada de trabalho intensiva (aceleração da produção num mesmo intervalo temporal) e extensiva (maior dedicação de tempo ao trabalho), facilitada fundamentalmente pelas novas tecnologias.

Sevcenko (2000) afirma que:

O professor ideal agora é um hibrido de cientista e corretor de valores. Grande parte de seu tempo deve ser dedicado a preencher relatórios, alimentar estatísticas, levantar verbas e promover visibilidade para si e seu departamento. O campus vai se reconfigurando num gigantesco pregão. O gerenciamento do meio acaba se tornando fim da universidade (p. 6-7).

Maués (2006, p. 8) afirma que a "nova organização do trabalho tendo como patrão a empresa é também outro fator que tem marcado a função docente". Observa-se que a Lei de Inovação Tecnológica também afeta o trabalho docente com a mudança da cultura acadêmica, instaurando um empresariamento da educação que ainda não se via com tanta clareza no setor

TrabalhoNecessário - www.uff.br/trabalhonecessario; Ano 8, № 10/2010. 
issn: $1808-799 \mathrm{X}$

ano 8 - número 10 - 2010

público, com a transformação do professor em empreendedor, produzindo novos valores e éticas que antes não faziam parte do universo acadêmico, como a corrida frenética por mais recursos, competitividade pelos editais, produzindo um "professor de pires na mão", um docente que vai se orientar para pedir recursos em tantos lugares/empresas quanto possíveis, procurando evitar a falência do seu grupo de pesquisa, sujeitando-se a perda da autonomia do saber, subordinando-se aos interesses mercantis que atrelam 0 conhecimento do docente às demandas do mercado. Essa busca por mais recursos produziu o "docente empreendedor competente", premiado pelo esforço individual, que consegue sair da universidade na penúria e voltar do mercado com o pires com alguns recursos para não deixar seu projeto de pesquisa falecer, ainda que com a venda de seus serviços.

O Sindicato Nacional dos Docentes da Educação Superior - ANDES (2004) em documento alerta que a Lei de Inovações Tecnológicas somada ao conjunto das suas contradições, privilegia apenas poucos pesquisadores e pequenos grupos, cujo objeto de pesquisa seja de interesse das empresas, que no final produz um capitalismo acadêmico, construindo também um novo ethos acadêmico.

Como analisa Mancebo (op. cit) essa nova forma de acumulação flexível produziu um docente que teve flexibilizado também as suas tarefas, com o caso do professor empreendedor, assumindo funções que antes eram desempenhadas por outros atores no interior da universidade, entre outras funções destaca-se até "a captação de recursos para viabilizar seu trabalho e até para o bom funcionamento da universidade" (p. 77). Segundo a Lei $10.973 / 2004$ o professor deve captar recursos no mercado oferecendo serviços de inovação tecnológica.

A transformação do professor empreendedor está expressa de forma clara no artigo 14 da legislação específica que possibilita ao docente ganhar um terço dos lucros em um projeto de inovação tecnológica que logre êxito. $E$ possibilita ao docente que tenha licença por seis anos para tentar uma carreira empresarial. Num contexto de enxugamento dos salários e das condições precárias de trabalho essa possibilidade soa com a chance de sair do pires 
issn: $1808-799 \mathrm{X}$

ano 8 - número 10 - 2010

para o banquete para muitos docentes. Maués (2006) afirma que medidas como essa alteram a natureza e o processo do trabalho docente.

As implicações do que chamo de pires na mão, da corrida frenética dos docentes por mais recursos, têm impactos diretos sobre a sua saúde e o adoecimento docente. Assunção e Oliveira (2009) analisam as redefinições do trabalho docente e as conseqüências para a saúde do trabalhador, embora sob - enfoque da educação básica, também se compara aos docentes da educação superior, pois a desregulação e a redefinição das atividades levou a intensificação do trabalho, produzindo também redefinições do docente com o tempo de trabalho, com efeitos negativos sobre a saúde. É desta forma que Maués (op. cit.) aponta a sobrecarga de trabalho, provocando desgastes físicos e emocionais, por provocar mudanças na organização do trabalho docente.

Com os cortes de verbas para a pesquisa apresentaram-se novas exigências para o trabalhador docente, emergindo uma nova regulação que abre brechas para a captura de recursos na esfera privada, produzindo um docente que sai numa corrida sem fim atrás dos recursos e editais, produzindo maior responsabilidade sobre este ante o sucesso ou o fracasso para o financiamento de seu projeto de pesquisa, com conseqüências sobre as condições de trabalho e de remuneração.

\section{Considerações Finais}

Ao fazer as considerações finais neste artigo é possível afirmar que as mudanças que marcaram o possível novo cotidiano da universidade pública brasileira estão intimamente ligadas com a estratégia de adequação da economia brasileira às recentes exigências do capitalismo e de sua (nova) base produtiva.

Uma universidade pautada pelos princípios de eficiência, produtividade e flexibilidade para atender os desafios do Estado neoliberal pode colocar em risco um projeto estratégico desenvolvimento e de soberania nacional pelo pragmatismo e imediatismo que marcam o mercado, suscetível a mudanças radicais em momentos de crises.

A reforma da educação e as políticas fundamentadas no paradigma gerencial que demarcou mudanças nas praticas e na cultura acadêmica foram 
issn: $1808-799 \mathrm{X}$

ano 8 - número 10 - 2010

processadas sob o discurso oficial da modernização racionalizadora, consagrando uma idéia de universidade moderna e produtiva, prestadora de serviços ao mercado, que desresponsabiliza o Estado pelo seu custeio.

A compreensão das repercussões desse novo cotidiano universitário sobre o trabalho docente não pode ser feita fora do contexto das transformações sócio-econômicas que perpassam a sociedade brasileira e que atinge diretamente as universidades públicas.

Tomando como exemplo a expressão que usei "pires na mão" para situar o trabalho docente na universidade pública, me refiro ao processo neoliberal e de sucateamento das universidades públicas que vem sendo implantado com rigidez pelos sucessivos governos brasileiros, atacando a pesquisa e a extensão.

O professor que produz pesquisa tem sido obrigado a "andar com o pires na mão", representando a busca por mais recursos para sua pesquisa, o que caracteriza um processo de precarização do trabalho docente, que está sujeito aos modelos de flexibilização que são a marca da atual configuração do capitalismo.

Esse pires na mão representa a tensão e o conflito em face da possibilidade de ver seu grupo de pesquisa fechar ante os escassos os recursos, produzindo uma subjetividade que revela sofrimento, stress diante das novas condições de trabalho docente, evidenciando conseqüências nefastas da reforma da educação superior em curso.

Com a lei de inovações tecnológicas a lógica capitalista adentrou 0 trabalho docente de forma impar, subordinou o docente ao capital produtivo e introduziu uma nova forma de proletarização, principalmente sob o ponto de vista da perda da autonomia. 
issn: $1808-799 \mathrm{X}$

ano 8 - número 10 - 2010

Referências Bibliográficas

ANDES. A contra-reforma da educação superior: uma análise do ANDES das principais iniciativas do governo Lula. Brasília, Agosto 2004.

ASSUNÇÃO, Ada Ávila \& OLIVEIRA, Dalila Andrade. Intensificação do Trabalho e Saúde dos Professores. Educação e Sociedade, v. 30, n. 107, p. 349-372, maio/agosto 2009.

BANCO MUNDIAL. O Ensino Superior: As Lições derivadas da experiência. Washington, DC: BIRD/BANCO MUNDIAL, 1994.

BRASIL, Lei 10.973 de 2 de dezembro de 2004. Dispõe sobre incentivos à inovação e à pesquisa científica e tecnológica no ambiente produtivo e dá outras providências. Diário Oficial de 03.12.2004, Seção I, Pág. 2.

BRASIL. MARE. Plano Diretor de Reforma do Estado. Presidência da República. Brasília, 1995.

CHAVES, Vera Jacob. A Política de financiamento da educação superior pública e da pesquisa no Brasil. In: NETO, Antonio Cabral; NASCIMENTO, IIma; LIMA, Rosangela. Política Pública de Educação no Brasil: Compartilhando saberes. Porto Alegre: Ed. Sulina, 2006.

- O público privado na Educação Superior Brasileira: a

Privatização da Universidade Pública. In: SILVA, Maria Abadia \& SILVA, Ronalda Barreto. A Idéia de Universidade. Brasília: Líber Editora, 2006.

Autonomia Universitária: A política do Banco Mundial para a educação superior brasileira. In: Helena Corrêa de Vasconcelos. (Org.). Múltiplos olhares sobre a educação superior: a pesquisa como fio condutor. 1a ed. Belém: UFPA/Centro de Educação, 2001.

CHAVES, Vera Jacob; MENDES, Odete da Cruz. REUNI: O contrato de gestão da educação superior brasileira. In: CHAVES, Vera Jacob; CABRAL NETO, Antonio; NASCIMENTO, Ilma (orgs). Políticas para educação superior no Brasil: velhos temas e novos desafios. São Paulo: Xamã, 2009.

CHAVES, Vera Jacob. Reforma do Estado e Privatização da Universidade Pública: Conseqüências sobre 0 trabalho docente. VI Seminário da REDESTRADO - UERJ, Rio de Janeiro, 2007. 
issn: $1808-799 \mathrm{X}$

ano 8 - número 10 - 2010

CHAUÍ, Marilena. A Universidade pública sob nova perspectiva. Revista Brasileira de Educação. Campinas, SP. №. 24, p. 5-15, Set-Dez 2003.

GENTILI, Pablo. A falsificação do consenso: simulacro e imposição na reforma educacional do neoliberalismo. Petrópolis: Vozes, 1998.

LÉDA, Denise Bessa. Trabalho docente no ensino superior sob o contexto das relações sociais capitalistas. In: $29^{a}$ Reunião Anual da ANPED, Caxambu, 2006. MANCEBO, Deise. Trabalho Docente: Subjetividade, Sobreimplicação e Prazer. Psicologia: Reflexão e Crítica, 2007.

MANCEBO, Deise; MAUÉS, Olgaíses; CHAVES, Vera Jacob. Crise e reforma do Estado e da Universidade Pública: implicações para o trabalho docente. Educar em Revista, Curitiba, n. 28, p. 37-53, Ed. UFPR, 2006.

MAUÉS, Olgaíses. O Trabalho docente no contexto das reformas. $28^{a}$ Reunião Anual da ANPEd, Caxambu, MG, 2005.

A Reforma da educação superior e o trabalho docente. VI Seminário da REDESTRADO - UERJ, Rio de Janeiro, 2007.

SEVCENKO, N. O Professor como corretor. Folha de São Paulo, São Paulo, 4 de Junho, 2000. Caderno Mais, p. 6-7.

SGUISSARD, Valdemar. Universidade Brasileira no Século XXI: Desafios do Presente. São Paulo: Cortez, 2009. 